\title{
PERFORMANCE OF A SENSORLESS SRM DRIVE FED FROM A PHOTOVOLTAIC SYSTEM
}

\author{
Ahmed Said Oshaba1,2 \\ 1-Power Electronics \& Energy Conversion Dep., Electronics Research Institute (ERI) \\ NRC Blg., El-Tahrir St., Dokki, 12311-Giza, Egypt \\ 2. Jizan University, Faculty of Engineering, Electrical Engineering Department, KSA \\ E-mail: oshaba68@hotmail.com,
}

\begin{abstract}
The paper presents the development and implementation of a new sensorless algorithm for estimating the rotor position of switched reluctance motor (SRM) over a wide range of operating conditions. The algorithm is designed to overcome difficulties in estimating the rotor position at starting as well as at the normal operation region. The algorithm is successfully implemented experimentally using SRM fed from a photovoltaic source which has a nonlinear operating nature. The results show improved performance at starting as well as when step changes in converter duty ratio or insulation levels occur. The results demonstrate clearly that the new algorithm ensures smooth starting without initial hesitation and reduces the torque ripples. The results presented are of prime importance to manufacturing companies leading to low cost reliable SRM drive systems for various industrial applications.
\end{abstract}

Keywords: SRM, Sensorless Algorithms, PV system, Performance analysis of SRM.

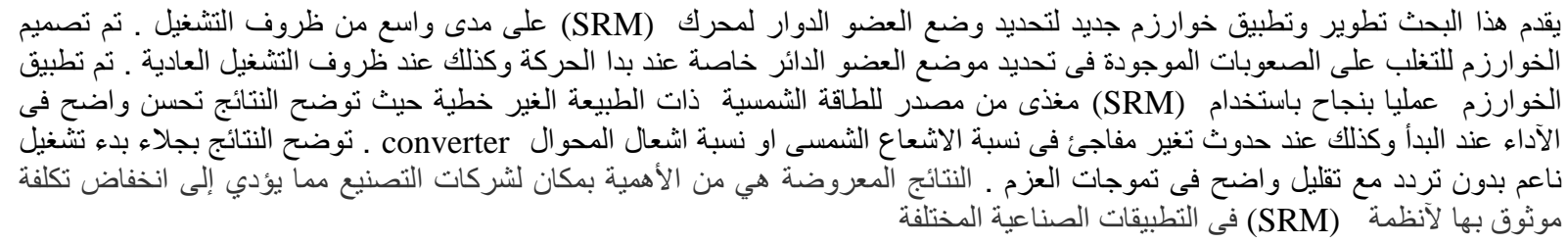

\section{Introduction}

Switched reluctance motors (SRM) have a wide range of industrial applications because of their advantages over conventional AC/DC Drives [1]. This is due to simple construction, ruggedness and inexpensive manufacturing potential. Various methods have used and applied to control SRM speed such as angle position control, phase current chopping control, fixed angle pulse width modulation (PWM) control, and variable angle PWM control [25]. However, difficulties in measuring rotor position made it quite complex to achieve smooth speed control of switched reluctance motors. Moreover, torque ripple, vibration and acoustic noise remain the main drawbacks for the wide spread of SRM applications [6-9].
To overcome these difficulties, effort was made to replace the position sensor with suitable estimation technique and a number of sensorless algorithms were suggested with little concern about motor starting [4,9]. However, these algorithms did not lead to smooth starting of switched reluctance motors which represent a major problem in assessing the performance of this type of motors and limited its industrial applications. This starting problem of switched reluctance motors becomes worse when the motor fed from a photovoltaic system (PV) which has a nonlinear function nature.

Intensive worldwide research plans over the last 
two decades led to a substantial development in photovoltaic industry. This appeared in the high reduction of solar cell production cost, enormous increase in solar cell efficiency and producing solar cells that are able to extract photovoltaic power over the full spectrum of the wave lengths. The idea of producing a photovoltaic plant that generates megawatts or connecting a photovoltaic system to the grid seemed unlikely to the most until the late 90 's,. However, this is not the case at present as thousands of plants rated at more than $1 \mathrm{MWp} \quad$ (peak watt) are now in service. This up rating of photovoltaic generator power represents the start of a new era of photovoltaic energy utilization .

A major use of PV systems currently being developed is in solar home systems, supplying basic electricity demand of rural population in developing countries and many other applications systems in remote areas where photovoltaic energy has proved to be an economical source of energy. Photovoltaic systems are used to drive many electric motors including SRM [24-26]. Photovoltaic generators exhibit highly nonlinear insulation dependent characteristics with poor voltage regulation [1-23]. Subsequently, careful attention must be considered when SRM is fed from a Photovoltaic source.

The paper presents a method for estimating the rotor position estimation of switched reluctance motors fed from a photovoltaic source. The method is successfully implemented and tested experimentally using a $8 / 6$ poles SRM fed from a photovoltaic system. The experimental results show a smooth starting and a good performance at steady state and when step changes occur with a significant reduction in torque ripples.

\section{Sensorless Techniques}

Speed control of SRM drives depends on signals measured from phase current, rotor position, and speed. Subsequently, the motor performance is significantly affected by the method used to obtain these signals in a particular application. Phase current and speed signals are usually measured with transducers, which increase the cost of the electronic controller and its packaging size. In the case of using a rotor position/speed transducer, the size of the motor housing and the cost are increased significantly. Emerging high-volume applications in heating, ventilation, and air conditioning (HVAC); fans; pumps; home appliances; automobile accessory drives; and many others are cost sensitive. The performance requirements for such applications are not high as that required for machine tool servo drives. Generally, the requirement of low cost with high performance for motor drives has placed the agenda of low-cost, sensor-based or sensorless technology at the forefront of present day research and development of motor drives[1-5]. SRM drives are no exception to this trend, as seen from the high degree of interest shown by industrial and academic researchers worldwide on this topic.

Rotor position measurement and estimation can be broadly classified into the two categories of acquisition schemes: continuous or discrete. Within these two categories, they can be further subdivided into sensor- and sensorless-based methods of rotor position measurement and estimation.

The sensorless methods of estimation can be classified into modern control-based and inductancebased estimation schemes. The inductance-based estimation methods exploit the inherent unique characteristic of the three-dimensional relationships among the flux linkages or inductance, current, and rotor position, and the availability of the first two variables leads to resolution of the third unknown, which is the rotor position. A number of methods exist using inductance-based estimation[1-4]. They in turn can be further divided into direct and indirect forms of inductance measurement [4,5]. The salient difference between these methods lies in which either the inductance is measured directly or by monitoring other variables. The modern control methods are based on observation and intelligent control techniques $[13,17]$. The observer-based methods use a state observer or a sliding mode observer, both of which essentially depend to an extent on the inductance slope for their convergence and functioning [11-23]. The observers are computationally intensive and have the problem of convergence in terms of the time taken to converge to the correct estimates. The intelligent control methods encompass estimators based on artificial neural networks and fuzzy control [11-23]. These methods are computationally less intensive compared to observer methods but due to their learning capability provide adaptive control. The accuracy of the rotor position estimation is not sufficient for highperformance applications, such as a position servo control application, but is acceptable in many other industrial applications. Most of the sensorless methods require phase currents and applied voltages for their estimation. The current can be sensed inexpensively, but the commercial voltage sensors with high bandwidth are expensive. Alternatively, a low-cost voltage sensor or estimator is realizable using control-level, isolated-gate drive signals and a dc source voltage magnitude [1-4].

The sensorless estimation scheme uses current changes to estimate the incremental inductance of the machine phase from which the rotor position is extracted [5-11]. Sensorless rotor position estimation 
is considered desirable because of compactness in weight and volume, lower cost due to elimination of the mechanical assembly and mounting associated with a rotor position sensor, and no rotating parts and no wear and tear, thus no maintenance requirements for its life [10-15].

The driving factor behind sensorless operation of any electrical drive including that of SRMs is the quest for low-cost drives with high performance. Three broad classes of rotor position estimation have emerged in research and development [5-23]:

1. Observer-based schemes give a continuous estimation of rotor position.

2. Incremental inductance-based measurement uses current rise time or fall time or its magnitude to obtain discretely the rotor position.

3. Inductance-based estimation of rotor position uses the two different techniques of demodulation and constant current or constant flux linkage applied to sensor signals and sensing phases, respectively, to give a continuous estimation.

\section{Sensorless Problems of SRM}

During standstill, the rotor position is unknown. For smooth starting of the drive, the relative position of the phases should be detected and proper phase should be chosen for excitation for driving the motor in the required direction. Excitation to any arbitrary phase will not result smooth starting. In literature, a number of sensorless algorithms for SRM drive are suggested $[4,5]$. Unfortunately, most of the existing schemes discuss the position estimation only during running condition. However, the sensorless operation at running condition only does not make much sense without successful starting,. The proper algorithm should give better position estimate during running as well as in starting.

The Feed-forward open loop estimation method presented in [4,5] use a train of pulses with initial frequency applied to each phase of the motor windings in a sequence according to the direction of rotation with $15^{0}$ phase shift while the difference between Toff and Ton angle is kept fixed. Though the method considered efficient during running conditions it does not provide smooth starting. Alternatively, a particular phase of the motor is excited for sufficient period of time and the rotor may be aligned along its axis [3-5]. Once the rotor is aligned, the position of all the phases with respect to the rotor is known and by appropriate switching logic the motor can start suitably. This method is described in $[1,2]$. However, the rotor may not get aligned to the required axis. The inductance profile of the test motor are designed in such a way that near both aligned and unaligned region there is a no-torque zone, when even under excitation the rotor will not experience any torque. Hence, originally if the rotor lies in the no-torque zone near unaligned region, it will not be aligned even with excitation. In that situation, one phase excitation may not be sufficient for alignment of the rotor. Two phases are used for reliable alignment. The major disadvantage of this method is that the motor may move backwards before actual starting commences.

The Flux-computation technique is described in [1-4]. During standstill, a pulse voltage may be injected to any phase and flux-linkage may be computed through the integration of voltage equation. From the measured current and computed flux, position at starting may be obtained from the stored flux-linkage characteristics in the same way as the running condition. Flux-linkage characteristics being symmetric along the aligned axis, it is not possible to estimate the absolute position of the rotor through flux-current method by single phase excitation. Theoretically, by giving excitation to two phases the exact rotor position of the different phases can be detected. In order to obtain accurate estimate of position, phases are to be excited for sufficient time so that sufficient flux builds up, otherwise at low flux and low current the estimation results will be erroneous. Besides, if the particular phase is near unaligned or aligned region, the estimated position will be error prone. The main difficulty with this method is that before the actual start, the rotor may move backward and a starting hesitation is observed. Hence, in this method (two phase excitation) special care is to be taken for avoiding such hesitation.

\section{New Sensoreless Method for SRM}

\subsection{Running Conditions of SRM}

Position can be detected most reliably at starting by applying excitation pulses to all phases successively The flux-linkage of any phase is computed as follows [1-5]:

$$
\begin{aligned}
& V=R i+d \psi(\theta, i) / d t \\
& \psi(\theta, i)=\int(V-R i) d t
\end{aligned}
$$


Data for the relation between $(\psi, i)$ at the aligned

Can be obtained through measurements similar to that shown in Fig. (1). and using appropriate interpolation method [4]. This discrete available data and unaligned positions can be extended to be continuous for the full range of $\psi$, and $\mathrm{i}$ values during the period between the positions (aligned $\theta=0$ and unaligned $\theta=2 \pi / \mathrm{N}_{\mathrm{r}}$ ). This data is experimentally measured by the following sequence:

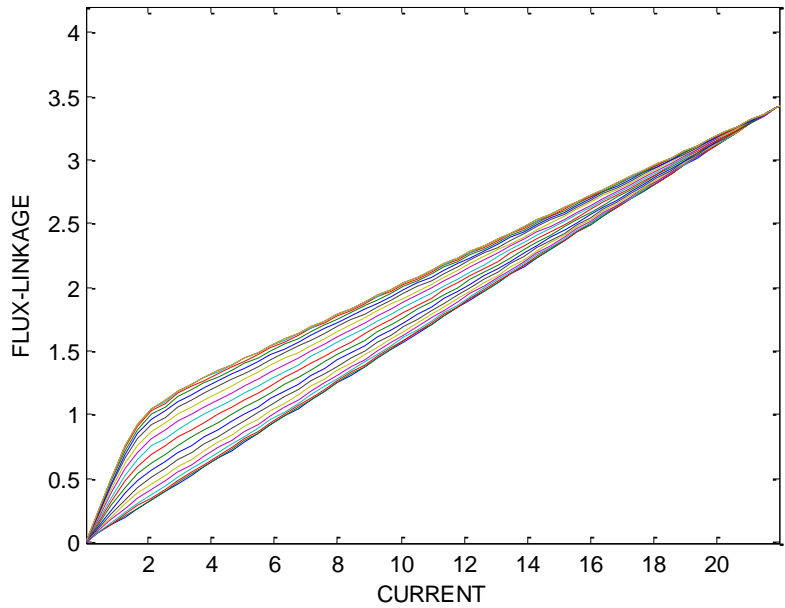

Fig. 1 Measured Flux linkage versus current curves ( by interpolations ).

At the aligned position, an AC voltage is applied to the phase winding then the current can be calculated. By current calculations, the impedance value can be estimated and then used to calculate both the inductance and flux linkage. On the other hand, rotor braking at the unaligned position, the same previous procedure can be used to calculate the flux linkage of this phase. The following relation can be used to estimate the intermediate $(\psi, \mathrm{i})$ curves [2].

$\psi(\theta, i)=L_{u} i+\left(\psi_{a}(i)-L_{u} i\right)\left(1-\cos \left(N_{r} \theta\right)\right) / 2$

It is evident that the model accuracy depends on how dense these curves are, while the increased number of curves between those two boundaries will make the model more memory demanding.

Otherwise, pre-computed $(\psi-i)$ characteristics is stored in a look-up table to compute position from the measured phase voltages and currents. From the measured voltage and current, flux-linkage of a phase is computed from equation (2). With known fluxlinkage and current, position can be looked-up from the stored data. There are several important issues involved in the position estimation method outlined above. These are listed as follows.
The $(\psi-i)$ characteristics are pre-computed. The pre-computed Characteristics are obtained by tests done under static conditions. These static tests do not take into account the non-idealities associated with the dynamic conditions under which the machine is operating. Such non idealities are related to two aspects:-

1- The eddy current effects in dynamic condition may influence the $\psi-i$ characteristics of the SRM. These influences may introduce an error in the estimated position.

2- The static $\psi-i$ characteristics do not take into effect the mutual coupling between the various phases during dynamic operation. It is shown that mutual fluxes can introduce errors in position estimate as much as $\pm 3^{\circ}$.

The static torque is calculated using the following equations.

$$
\begin{aligned}
& \text { Coenergy }=W^{\backslash}=\int \psi(\theta, i) . . d i \\
& \text { static..torque }=T_{\text {static }}=d W^{\backslash} / d \theta
\end{aligned}
$$

From equations (4) and (5) a similar static torque matrix can be estimated where current will give the row index and $\theta$ will give the column index [4].

The value of developed torque can be calculated from the value of static torque Fig. (2).

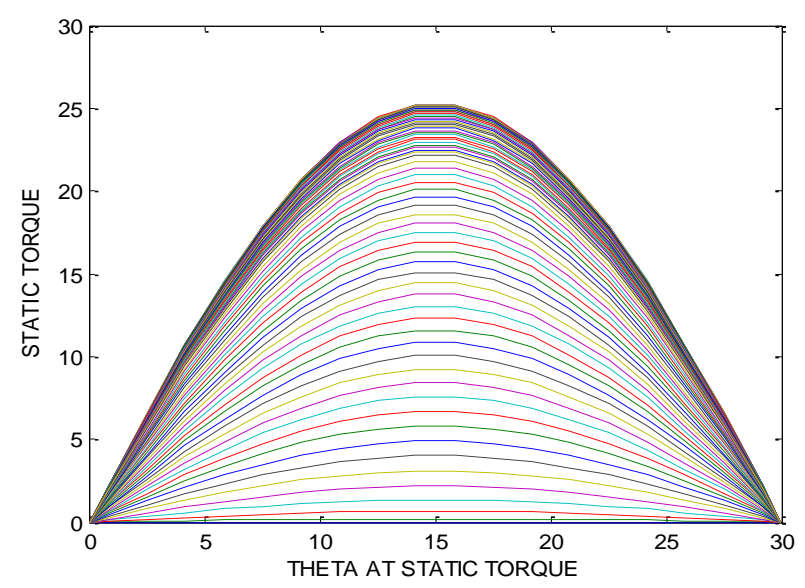

Fig. 2 Measured theta-static torque family of curves.

The value of actual speed can be calculated from the following mechanical equations: 


$$
\frac{d \omega}{d t}=\frac{1}{J}\left(T_{d e v}(\theta, i)-T_{\text {load }}-B \omega\right)
$$

Where, the speed error obtained from the difference between the rotor speed and its reference is amplified and limited in the speed controller, which usually is a proportional-plus-integral (PI) controller the output of this is load torque value.

The value of rotor angular displacement $\theta$ can be calculated from the following equation:

$$
d \theta / d t=\omega
$$

\subsection{Starting Conditions of SRM}

On starting, a test excitation signal is employed to select the appropriate phases to be excited. Direct control of the current injected during starting ensures test pulse in the non-saturated zone of $(\psi-i)$ characteristics.

The angle $\delta$ corresponding to the displacement of phase $\mathrm{A}$ in relation to another phase is given by:

$\delta=2 \pi\left(\frac{1}{N_{r}}-\frac{1}{N_{s}}\right)$

Also the positive period of phase is determined by the following equation:

duty period $=2 \pi\left(\frac{1}{q N_{r}}\right) C_{r}$

And $\mathrm{C}_{\mathrm{r}}$ can be calculated by the following equation.

$$
C_{r}=2 \pi\left(\frac{1}{\beta_{r}}-\frac{1}{\beta_{s}}\right)
$$

Duration of negative current pulses is depended on the stored energy in phase winding [1-5].

\subsection{Proportional Integral Parameter Tuning}

The introduction of integral control action reduces the steady-state error and. creates a restoring force that is proportional to the sum of all past errors multiplied by time. In this case, conventional adaptive controller for starting is used. The controller algorithm can be given as follows:

$$
\operatorname{err}(t)=\operatorname{ref}(t) .-\operatorname{act}(t)
$$

where $\operatorname{act}(t)$ is the actual output of the system, $r e f(t)$ is the reference input of the system, $\operatorname{err}(t)$ is the error signal between $\operatorname{act}(t)$ and $\operatorname{ref}(t)$.
For a constant value of error, the value of $\Sigma(E \Delta t)$ will increase with time, causing the restoring force to get larger and larger. Eventually, the restoring force will get large enough to overcome friction and move the controlled variable in a direction to eliminate the error.

Starting controller (turn on controller)

$u(t)=K_{p} . . e r r(t) .+. K_{i} . . \int \operatorname{err}(t) . . d(t)$

Where $u(t)$ is the output of controller, $K_{p}$ and $K_{i}$ are proportional and integral gains respectively and this gains are adaptation to obtain a good model for starting.

\section{Implementation}

The system considered to implement this algorithm is shown in Fig 3. It consists of four blocks as follows:

The first block is a PV system where the output of this block of the DC source voltage. And be in control of this output voltage is the solar radiation values (insulation value) and duty cycle ratio of PV converter values.

The secondary block is the $\mathrm{H}$ converter where the input of this converter are the PV output DC voltage and the turn on angle value from starting control system while the output of $\mathrm{H}$ converter is the pulses square wave voltage $((+-0)$ voltage $)$.

The third block is the phase motor model where the input of this motor is the pulses square wave voltage from $\mathrm{H}$ converter while the output of this motor model the instantaneous pulses phase current and instantaneous pulses phase developed torque.

The fourth block is the motor mechanical system and starting control model where the input of this block of instantaneous pulses phase developed torque and obtained the total instantaneous developed torque from the following equation

$$
T_{\text {total.dev }}=T_{\text {a.dev }}+T_{b . d e v}+T_{c . d e v}+T_{d . d e v}
$$

While the displacement angle (calculation from motor speed) is output of mechanical system where the motor speed is calculate by the following equation

$$
\frac{d \omega}{d t}=\frac{1}{J}\left(T_{d e v}(\theta, i)-T_{\text {load }}-B \omega\right)
$$


And the displacement angle can be calculated

From the following equation

$\frac{d \theta}{d t}=\omega$

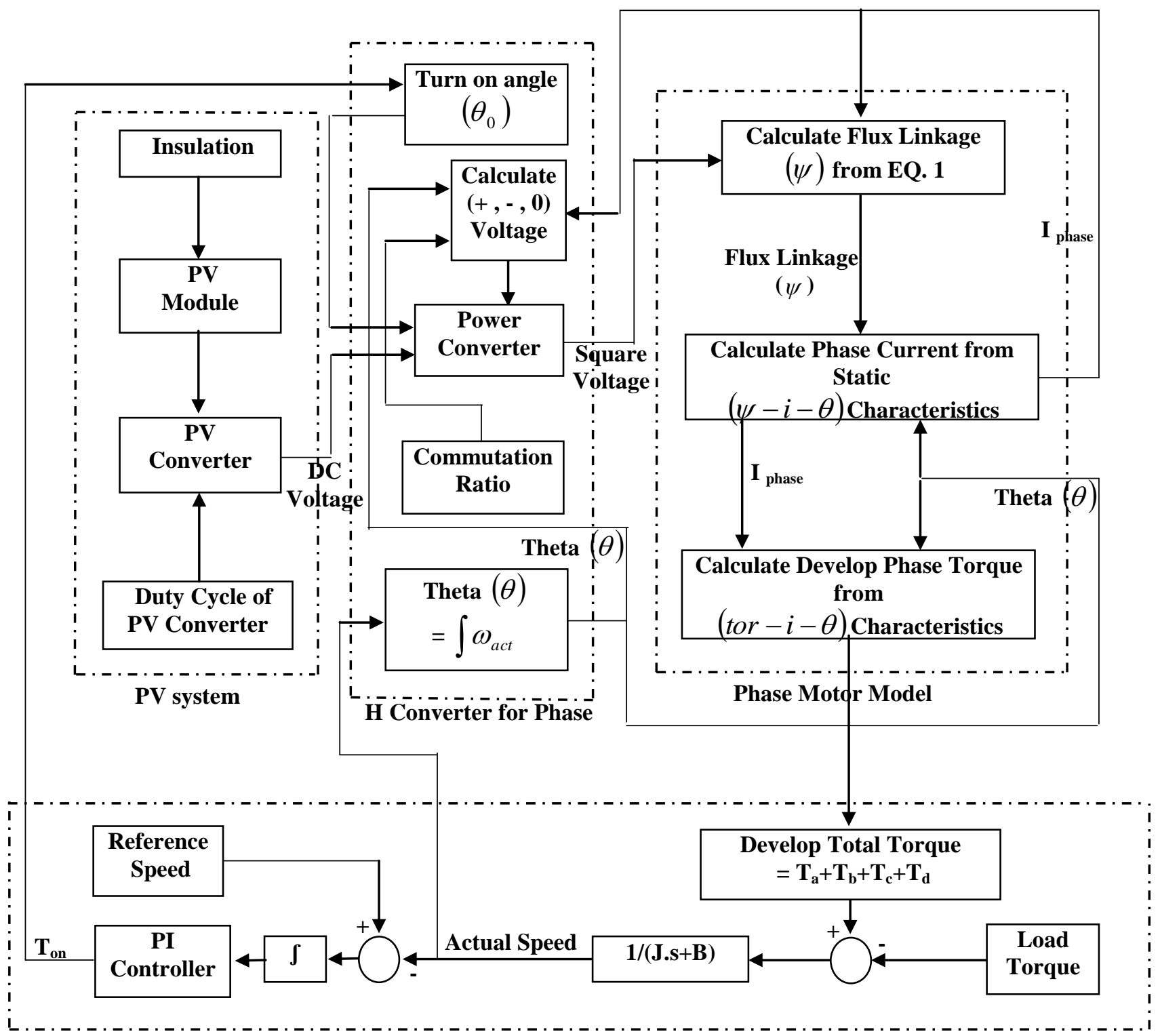

Motor Mechanical System and Starting Control Model

Fig. 3 . Sensorless diagrame for one phase SRM from four phases is suppled by PV system.

\subsection{Switched Reluctance motor}

The SRM has salient poles on both the stator and rotor. Therefore, it is referred to as a doubly salient poles machine. Also the motor winding is located only on the stator side. However, the rotor has neither windings nor magnets and is built up from a stack of steel laminations.
Each phase consists of two series connected windings on diametrically opposite poles. Thus, the eight -stator poles constitute the four phases [2]. The number of poles on both the stator and the rotor is usually unequal. This is to 
avoid the eventuality of the rotor being in a state of producing no initial torque, which occurs when all the rotor poles are locked in with the stator poles $[1,2]$.

The construction of the SRM used in this study is shown in Fig. 4.

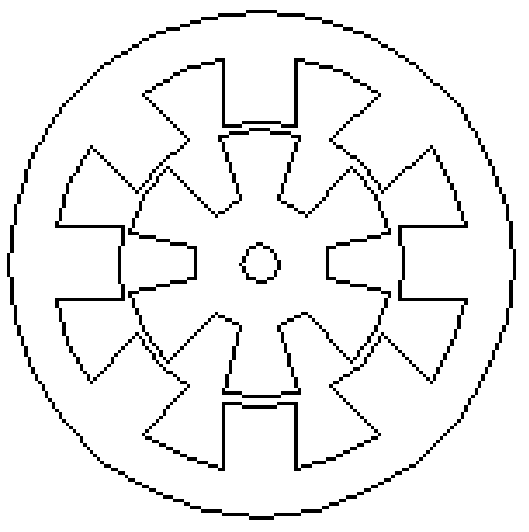

Fig 4. SRM diagram ( $8 / 6$ pole Motor).

The SRMs have the advantage of reducing copper lost while its rotor is winding. Its stampings are made preferably of silicon steel, especially in higher efficiency applications, and for aerospace application the rotor operates at very high speeds, requiring the use of cobalt, iron and other variants. The air gap is kept as minimal as possible $(0.1 \mathrm{~mm}$ to $0.3 \mathrm{~mm})$, and the rotor and stator pole arc should be kept the same. It is advantageous if the rotor pole arc is larger than the stator pole arc.

Normal operation of SRM requires sequential switching of different phase windings to DC mains while the rotor is moving. The output torque depends on the current level and rotor position. The current pulses are ideally timed to coincide with the positive torque production segments of the inductance waveforms.

This current produces pulses developed torque in phases. Which leads to the existence of torque ripple in the motor output and to reduce this ripple the need to increase the number of pulses per period by increasing the number of motor phases. Where:

$T_{\text {total.dev }}=T_{\text {a.dev }}+T_{\text {b.dev }}+T_{\text {c.dev }}+T_{\text {d.dev }}+\ldots$.

There are performance and cost tradeoffs between number of stator poles (number of windings) and number of phases. Since more poles and/or phases result in better performance and higher cost. It has been shown that the 4 or 5 phases SRM has better performance $[4,5]$.

Therefore in this paper, the motor was used to reduce the torque ripple and obtaining the good performance is four phases. It was found that most of the SRM applications You need to minimum torque ripple [1-5].

\subsection{Photovoltaic Generator}

The chosen generator have two series modules each of 36 cells, Hence Ns $=72$ cell. The number of branches is taken as $\mathrm{Np}=6$ branches to allow for starting current and/or operation at lower irradiation level. The overall voltage of the photovoltaic generator $\mathrm{V}$ is expressed in the following from [24-26]:

$$
\mathrm{V}=0.0731 * \mathrm{~N}_{\mathrm{s}} * \mathrm{Z}_{1}-\left(0.05 * \mathrm{~N}_{\mathrm{p}} * \mathrm{I}\right)
$$

Where:-

$\left.\mathrm{Z}_{1}=\mathrm{Ln}(\mathrm{XX}-\mathrm{I}+\mathrm{YY}) / \mathrm{YY}\right)$

$\mathrm{XX}=\mathrm{I}_{\mathrm{ph}} * \mathrm{~Np} * \%$ irradiation leve

$\mathrm{YY}=0.0005 * \mathrm{~Np}$

$\mathrm{V}$ and $\mathrm{I}$ are the average terminal voltage and current from cells, respectively, Iph is the photovoltaic current. This current is chosen to be of 0.8 ampere which is proportional to an irradiation level that equals $100 \%\left(1000 \mathrm{watt} / \mathrm{cm}^{2}\right)(3)$, while the open circuit voltage is taken as 0.54 volt. Figure 5 shows the V-I characteristics of the photovoltaic generator used in this study while the maximum power versus the irradiation level is shown in Fig 6

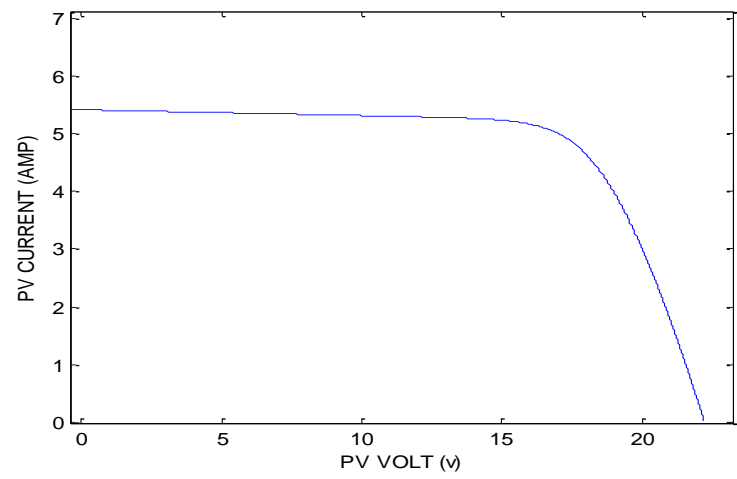

Fig. 5 I $\sim$ V characteristics of the PV generator 


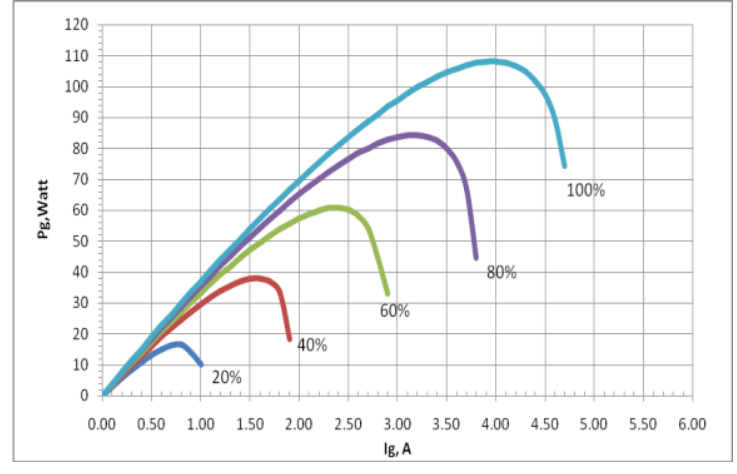

Fig. 6 Maximum power versus output current

\section{Results}

The SRM is supplied from th PV supply and the new

sensoreless algorithm is used to predict the rotor position and the system is used to control the input voltage sequence. The motor speed is measured at starting and the results is shown in Fig. 7 which illustrate smooth starting with no hesitation which substantiate the efficiency of the new algorithm used to estimate the rotor position. It must be emphasized that the new algorithm operates successfully over the whole range of operation as extracted from the results. The same conclusion can also be obtained when the insulation level or converter duty cycle is changed as shown in Fig. 8 and Fig 9 which illustrate spead variation when changes occur in insulation level or duty cycle respectively.

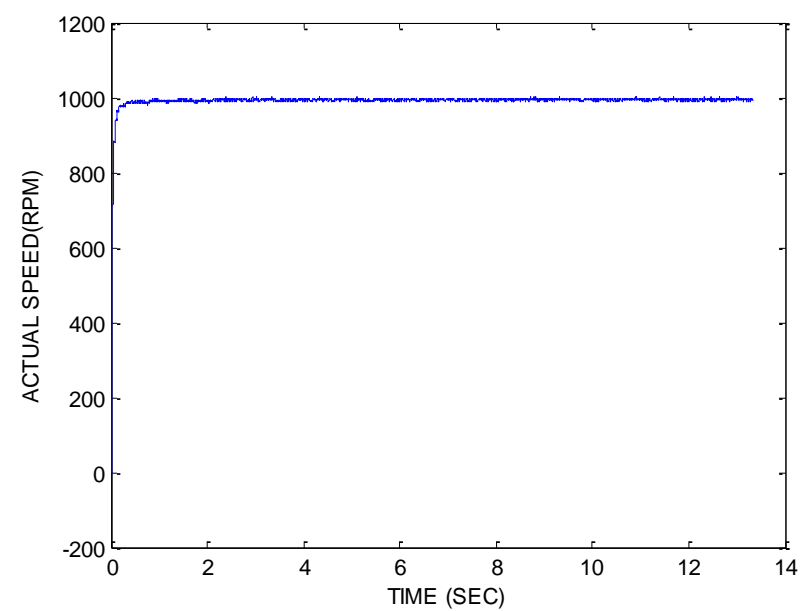

Fig. 7 SRM speed variation versus time at starting.
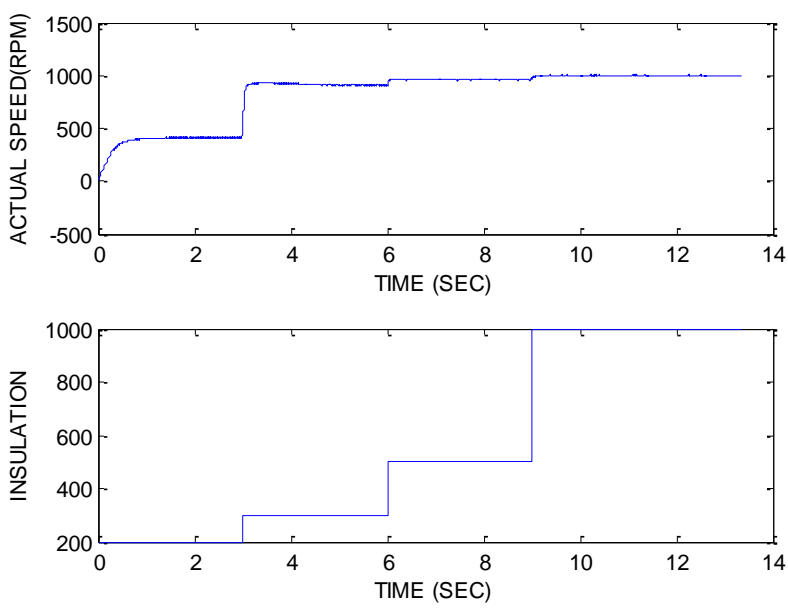

Fig. 8 Effects of changes in insulation level on speed.
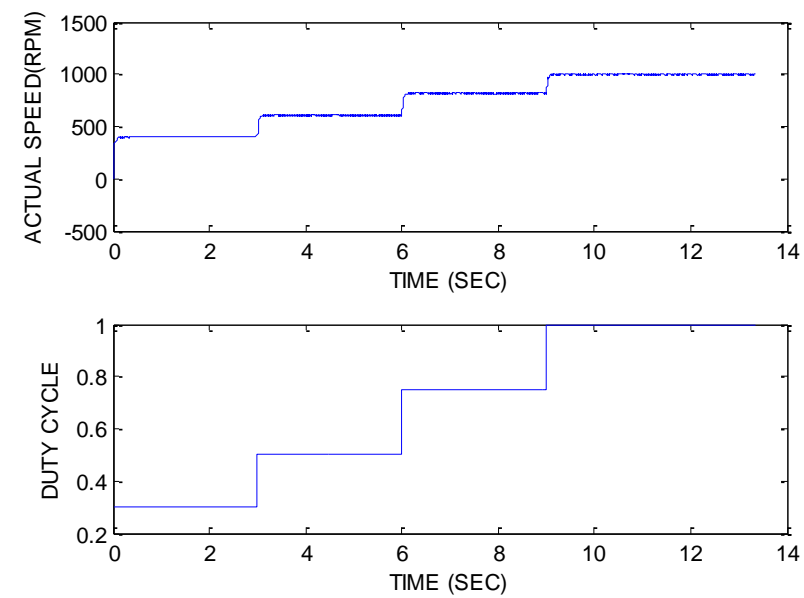

Fig. 9 Effects of changes in duty ratio on speed.

The four phases stator current at constant insulation and constant duty cycle ratio for PV converter is shown in Fig 10. From this curve it can be shown that the angle between phases is . Also, Fig. 11 shows one pulse for the phase current and flux linkage predicted by this method along with the applied voltage. 


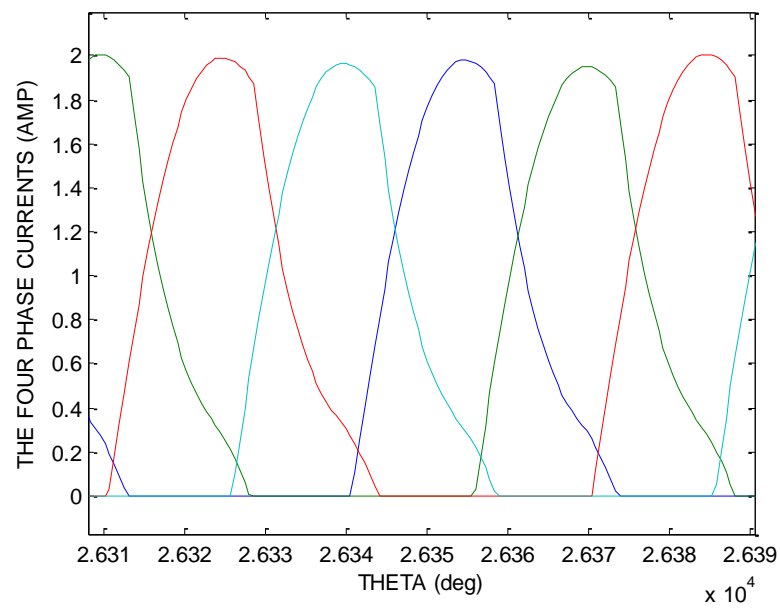

Fig. 10 Four phases currents.

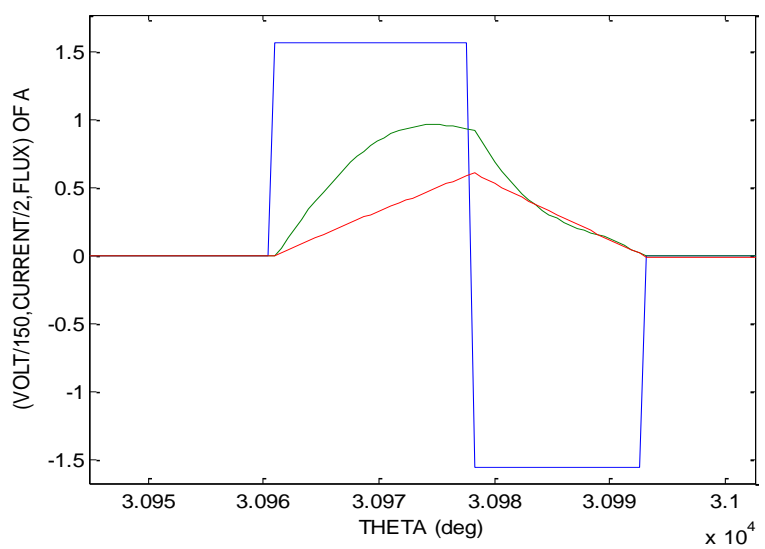

Fig. 11 The stator phase (voltage/150, current/2 and flux) curve.

\section{Conclusions}

This paper presented a new sensorless algorithm for estimating the rotor position of SRM. The method is implemented experimentally using a $8 / 6$ four phases switched reluctance motor fed from a photovoltaic system. The results illustrate that performance of SRM is significantly improved at both normal and starting conditions. Improved transient characteristics have also been observed if the duty ratio or insulation level is changed. This conclusion was obtained when the motor is fed from a PV system which has nonlinear characteristic nature which indicates that better performance will be obtained when a constant DC source is used. The new algorithm has been easily implemented experimentally and can be used for on line application which increases the industrial applications of SRM.

\section{References:-}

[1] Dan Jones, "Present and future applications of switched reluctance motors and drives", SMIC '99 conference, October 1999, Tokyo, Japan.

[2] J.M. Stephenson and J. Corda "Computation of Torque Current in Double Salient Reluctance Motors From Nonlinear Magnetization Data", proceedings IEE,vol.126, No.5,May 1979, pp. 393-396.

[3] J. Corda and J.M. Stephenson "Analytical Estimation of the Minimum and Maximum Inductances of a Double-Salient Motor ", Proceedings of the International Conference on Stepping Motors and Systems, University of Leeds, UK, September 1979, pp. 50-59.

[4] Ahmed Oshaba, "Analysis and Control of SRM", Ph.D. Thesis, Cairo Univ., FOE, April, 2004.

[5] Shuyu Cao, and K.J. Teseng, "A New Method for Accurate Analytical Modeling of Switched Reluctance Motor", PEDES'98 Vol. II, December 1998 pp.540-545.

[6] C. Rochford, R.C. Kavanagh, M.G. Egan and J.M.D. Murphy "Development of Smooth Torque in Switched Reluctance Motors Using Self-Learning Techniques", ENE'93, pp. 14-19.

[7] J.J. Gribble P.C. Kjaer and T.J.E. Miller "Optimal Commutation in Average Torque Control of Switched Reluctance Motors", IEE Proc.-Electric Power Appl., vol. 146, No. 1, January 1999, pp. 2-10.

[8] Khwaja M. Rahman, Suresh Gopalakrishnan, Babak Fahimi, Anandan Velayutham Rajarathnam and M. Ehsani "Optimized Torque Control of Switched Reluctance Motor at All Operational Regimes Using Neural Network", IEEE Transations on Industry Applications, vol. 37, NO. 3, May/June 2001, pp. 904-913.

[9] Krzysztof Russa, Iqbal Husain and Malik E. Elbuluk "A Self-Tuning Controller for Switched Reluctance Motors", IEEE Transactions on power electronics, vol. 15, No.3, May 2000.

[10] S. M.Alghuwainem, "Steady-State Performance of DC Motors Supplied from Photovoltaic Generators with Step- Up Converter “, IEEE Trans. on E.G.Vol.EC7, No. 2,June 1992,pp.267-272.

[11] Chen H. \& Gu J. J. (2010). "Implementation of the Three-Phase Switched Reluctance Machine System for Motors and Generators", IEEE/ASME Transactions on Mechatronics, Vol.15, No.3, June 2010, 421-432, ISSN 10834435 . 
[12] Naayagi R. T. \& Kamaraj V. (2005). "Shape Optimization of Switched Reluctance Machine for Aerospace Applications", Proceedings of 31st Annual conference of IEEE Industrial Electronics Society, pp. 1748-1751, ISBN 07803-9252-3, Raleigh, November 2005, IEEE Industrial Electronics Society, Los Alamitos.

[13] Liu W. \& Song S. (2006). "Application of Fuzzy Control in Switched Reluctance Motor Speed Regulating System", Proceedings of International Conference on Computational Intelligence for Modelling, Control and Automation, pp. 72-72, ISBN 0-7695-2731-0, Sydney, November 2006, Patrick Kellenberger, Sydney.

[14] K. M. Rahman, B. Fahimi, G. Suresh, A. V. Rajarathnam, and M. Ehsani, "Advantages of switched reluctance motor applications to EV and HEV: Design and control issues", IEEE Trans. Ind. Appl., vol. 36, no. 1, pp. 111-121, Jan./Feb. 2000.

[15] K. M. Rahman and S. E. Schulz, "Design of high efficiency and high density switched reluctance motor for vehicle propulsion", IEEE Trans. Ind. Appl., vol. 38, no. 6, pp. 1500-1507, Nov./Dec. 2002.

[16] T. J. E. Miller, "Optimal design of switched reluctance motors", IEEE Trans. Ind. Electron., vol. 49, no. 1, pp. 15-27, Feb. 2002.

[17] R. B. Inderka, M. Menne, and R. W. A. A. De Doncker, "Control of switched reluctance drives for electric vehicle applications", IEEE Trans.Ind. Electron., vol. 49, no. 1, pp. 48-53, Feb. 2002.

[18] I. Husain and S. A. Hossain, "Modeling, simulation, and control of switched reluctance motor drives", IEEE Trans. Ind. Electron., vol. 52, no. 6, pp. 1625-1634, Dec. 2005.
[19] A. K. Jain and N. Mohan, "Dynamic modeling, experimental characterization, and verification for SRM operation with simultaneous twophase excitation", IEEE Trans. Ind. Electron., vol. 53, no. 4, pp. 1238-1249, Jun. 2006.

[20] Jae-Hak Choi, Joonseon S. Ahn and Ju Lee, "The Characteristic Analysis of Switched Reluctance Motor Considering DC-Link Voltage Ripple on Hard and Soft Chopping Modes", IEEE transactions on magnetics, Vol. 41, No.10, pp. 4096-4098, Oct. 2005.

[21] X. D. Xue, K. W. E. Cheng, and S. L. Ho, “A position stepping method for predicting performances of switched reluctance motor drives", IEEE Trans. Energy Convers., vol. 22, no. 4, pp. 839-847, Dec. 2007.

[22] J. G. Amoros and P. Andrada, "Sensitivity analysis of geometrical parameters on a doublesided linear switched reluctance motor", IEEE Trans. Ind. Electron., vol. 57, no. 1, pp. 311319, Jan. 2010.

[23] R. Krishnan, "Switched Reluctance Motor Drives-Modeling, Simulation, Analysis, Design, and Applications", Boca Raton, FL: CRC Press, 2001.

[24] Yousry Atia, "Photovoltaic Maximum Power Point Tracking Using SEPIC Converter", Engineering Research Journal (ERJ), Shebin El-Kom Journal, Vol.36, No.4, October 2009.

[25] E. Matagne, Chenni R, El Bachtiri R., "A photovoltaic cell model based on nominal data only", International Conference on Power Engineering, Energy and Electrical Drives, 2007. Powereng 2007. 12-14 April 2007 Setubal, Portugal.

[26] M. Zahran, A. Hanafy, 0. Mahgoub and M. Kamel, "FLC Based Photovoltaic Battery Diesel Hybrid System Management and Control", 28th IEEE Photovoltaic Specialists Conference", September 15-22, 2000, Anchorage Hilton, Anchorage, Alaska, USA, 07803-5772-8/00@ 2000 IEEE. 